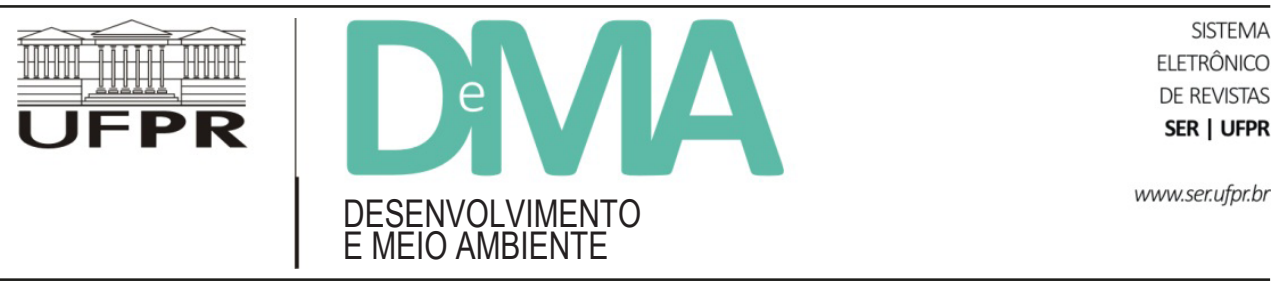

\title{
Transposição do rio São Francisco e a vulnerabilidade sociodemográfica: desafios ao bem-estar da população sertaneja
}

\author{
Transposition of the São Francisco River and \\ socio-demographic vulnerability: challenges to the \\ well-being of the countryside population
}

\author{
Paulo Victor Maciel da COSTA ${ }^{1 *}$, Ricardo OJIMA ${ }^{1}$ \\ ${ }^{1}$ Universidade Federal do Rio Grande do Norte, Natal, RN, Brasil. \\ *E-mail de contato: paulovictorma22@hotmail.com
}

Artigo recebido em 30 de abril de 2020, versão final aceita em 04 de setembro de 2020, publicado em 18 de dezembro de 2020.

RESUMO: O principal objetivo deste trabalho consiste em verificar como a mobilidade populacional decorrente da obra da transposição do rio São Francisco pode intensificar a vulnerabilidade sociodemográfica dos espaços urbanos da Área de Influência Direta (AID) desse empreendimento. O Projeto de Transposição localiza-se no semiárido setentrional do Nordeste brasileiro, espaço marcado pelas frequentes secas e pela desigualdade social e econômica. Originalmente destinado a mitigar os efeitos da seca, o Projeto de Transposição, em parte, traz consigo impactos não somente ambientais, mas principalmente sociais e demográficos. Nesse contexto, a mobilidade populacional é uma das questões demográficas decorrentes do Projeto de Transposição, por ser uma componente capaz de mudar rapidamente o tamanho e a composição da população nas áreas impactadas, que traz preocupações sobre as questões sociais (pobreza e exclusão social). No Brasil, pouco se tem abordado sobre a dimensão dos deslocamentos populacionais em torno da temática dos megaprojetos, ainda mais considerando os aspectos da vulnerabilidade sociodemográfica. Com base em informações do Censo Demográfico de 2010 e no arcabouço teórico de literaturas nacionais e internacionais que versam sobre a temática, buscou-se criar um índice sintético de vulnerabilidade sociodemográfica para analisar os impactos da mobilidade populacional decorrente do Projeto de Transposição. Os principais resultados mostram que o Projeto de Transposição agrava, em certa medida, os desafios a serem enfrentados pela população dos lugares mais próximos aos canais da obra, 
haja vista a fragilidade de capital humano (saúde, educação) e físico (habitação, deslocamento) dos migrantes residentes na AID.

Palavras-chave: semiárido setentrional; rio São Francisco; Projeto de Transposição; dinâmica demográfica; vulnerabilidade sociodemográfica.

ABSTRACT: The main objective of this work is to verify how the population mobility resulting from the transposition of São Francisco River, can intensify a socio-demographic vulnerability of the urban spaces of the Area of Direct Influence (AID in Portuguese) of this enterprise. The Transposition Project is located in the northern semiarid region of northeastern Brazil, a place marked by frequent droughts and social and economic inequality. Originally designed to mitigate the effects of drought, the Transposition Project, in part, brings with it not only environmental, but mainly social and demographic effects. In this context, population mobility is one of the demographic issues arising from the Transposition Project, as it is a component capable of rapidly changing the size and composition of the population in the impacted areas, raising concerns about social issues (poverty and social exclusion). In Brazil, little has been discussed about the dimension of population displacements around the theme of megaprojects, especially considering the aspects of socio-demographic vulnerability. Based on information from the 2010 Demographic Census and on the theoretical framework of national and international literature on the theme, an attempt was made to create a synthetic index of socio-demographic vulnerability to analyze the effects of population mobility resulting from the Transposition Project. The main results show that the Transposition Project worsens, to a certain extent, the challenges to be faced by the population of the places closest to the construction channels, given the fragility of human (health, education) and physical (housing, displacement) capital of migrants residing in AID.

Keywords: Northern semiarid; São Francisco River; Transposition Project; demographic dynamics; sociodemographic vulnerability.

\section{Introdução}

O principal objetivo deste trabalho consiste em verificar como a mobilidade populacional decorrente da obra da transposição do rio São Francisco pode intensificar a vulnerabilidade sociodemográfica dos espaços urbanos da Área de Influência Direta (AID) desse empreendimento. É na AID onde estão localizados os municípios que são afetados, de forma mais incisiva, pela obra dos canais da transposição.

Dada a monumental dimensão estrutural e níveis de impactos, o Projeto de Transposição, como aqui será chamado, traz preocupações não somente ao meio ambiente, mas principalmente para as problemáticas social e demográfica. A atração de mão de obra, por exemplo, poderia exigir maiores esforços por parte da gestão municipal no atendimento aos serviços básicos, como saúde, educação, segurança e moradia. Além disso, a imagem da transposição e de seus possíveis impactos positivos também pode ser um dos fatores de atração populacional. Assim, o não atendimento a essas demandas pode agravar o cenário de vulnerabilidade social preexistente, podendo reproduzir a pobreza e a exclusão social nas áreas afetadas ao impulsionar o processo de urbanização.

Dito isto, a vulnerabilidade sociodemográfica é uma abordagem mais analítica do que conceitual e a partir dela é possível aferir a capacidade de resposta e adaptação dos atores (indivíduos, famílias 
e lugares) aos riscos acentuados pelas tendências e características da estrutura e dinâmica da população (Rodríguez, 2001; Cepal, 2002; Busso, 2005; Rodríguez, 2006), entre eles os deslocamentos populacionais. Assim, a vulnerabilidade aqui é definida como a menor capacidade de resposta e adaptação aos riscos sociodemográficos, intensificados pelos possíveis efeitos da mobilidade populacional decorrente do empreendimento sobre a população residente na AID.

A dinâmica migratória, portanto, é uma das principais componentes demográficas que promete mudanças significativas na vulnerabilidade sociodemográfica, haja vista que pode afetar tanto a distribuição como a composição da população da AID em um espaço de tempo relativamente curto. Ou seja, o perfil da seletividade migratória apresenta impactos nas características da população que extrapolam a análise da sua contribuição apenas sobre o volume populacional. Aliados à migração, temos também os deslocamentos pendulares, que trazem preocupações ao planejamento das cidades, visto que são um fenômeno atrelado ao processo de transição urbana, o que pode acarretar a ampliação de demandas por serviços públicos nas configurações regionais e que vêm se manifestando de forma mais intensa nos últimos anos, mesmo nos municípios não metropolitanos (Ojima \& Marandola Jr., 2012).

Para reduzir a vulnerabilidade sociodemográfica, a literatura destaca o papel dos ativos e da estrutura de oportunidades (Kaztman, 1999). Essa redução se dá à medida que as famílias adquirem capacidades e ativos necessários. Dessa maneira, eles podem reduzir seus riscos à pobreza e à exclusão e, assim, alcançar o bem-estar social por meio do capital humano (capacidade física e intelectual para se inserirem no mercado de trabalho e que pode ser potencializada pelo investimento em saúde e educação), do capital social (redes sociais, como reciprocidade, confiança, contatos, acesso à informação e à proteção social e assistencial) e do capital físico (acesso à moradia, a serviços básicos de infraestrutura e a bens duráveis). Assim, a limitação de recursos, ou mesmo a falta de capacidade para gerenciá-los, indica vulnerabilidade a dois riscos sociais: a pobreza e a mobilidade socioeconômica descendente (Cepal, 2002).

Dessa maneira, a articulação desse conjunto de ativos, originários na comunidade, no mercado e no Estado, pode ser considerada uma estrutura de oportunidades fundamental para o processo de adaptação aos riscos sociodemográficos (Kaztman, 1999; Rodríguez, 2006). A estrutura de oportunidades, conforme Kaztman (1999), refere-se ao acesso a bens, a serviços e ao desempenho de atividades que podem facilitar o aproveitamento de outras oportunidades para o alcance do bem-estar.

Portanto, a mobilidade populacional pode trazer consigo limitações adicionais ao enfrentamento dos riscos sociais pela população no Semiárido nordestino, que, vulnerável socialmente, não dispunha dessa estrutura de oportunidades. Em outras palavras, por já ser considerado um lugar desprovido de ativos, suas estratégias de respostas já são limitadas, e características populacionais como tamanho, composição demográfica, localização residencial, entre outras, podem limitar ainda mais aquelas estratégias. Neste contexto, o debate de fundo sobre os determinantes ambientais da condição de vulnerabilidade na região passa a ser rediscutido sob uma perspectiva multidimensional, na qual as variáveis sociodemográficas têm papel relevante nas análises. Assim, a mobilidade populacional pode ser considerada como uma das principais ca- 
racterísticas da dinâmica demográfica, engendrando preocupações sobre o cenário de vulnerabilidade sociodemográfica, em especial nos espaços urbanos das áreas de influência do Projeto de Transposição.

\section{Procedimentos metodológicos}

O recorte geográfico privilegiado por este estudo são as áreas de influência do Projeto de Transposição, definidas pelo Estudo de Impacto Ambiental (EIA) e pelo Relatório de Impacto Ambiental (RIMA) do referido projeto (Figura 1). Parte-se dessa definição, pois é possível verificar a ausência de uma análise dos fatores sociodemográficos nestes estudos e, portanto, entendemos que seria necessário qualificar melhor a discussão destes aspectos populacionais para além do reducionismo de uma avaliação focada apenas no crescimento populacional. Além disso, trata-se de uma região de estagnação do crescimento populacional, com diversos municípios que apresentam até crescimento negativo. Diante disso, a dimensão migratória desempenha papel central no que se refere às transformações das características demográficas, mesmo quando o ritmo de crescimento populacional seja nulo ou decrescente.

Ao considerar o nível de impacto do empreendimento, o EIA-RIMA definiu duas áreas de influência, a direta e a indireta, a partir de critérios ambientais, econômicos e técnicos (Figura 1).

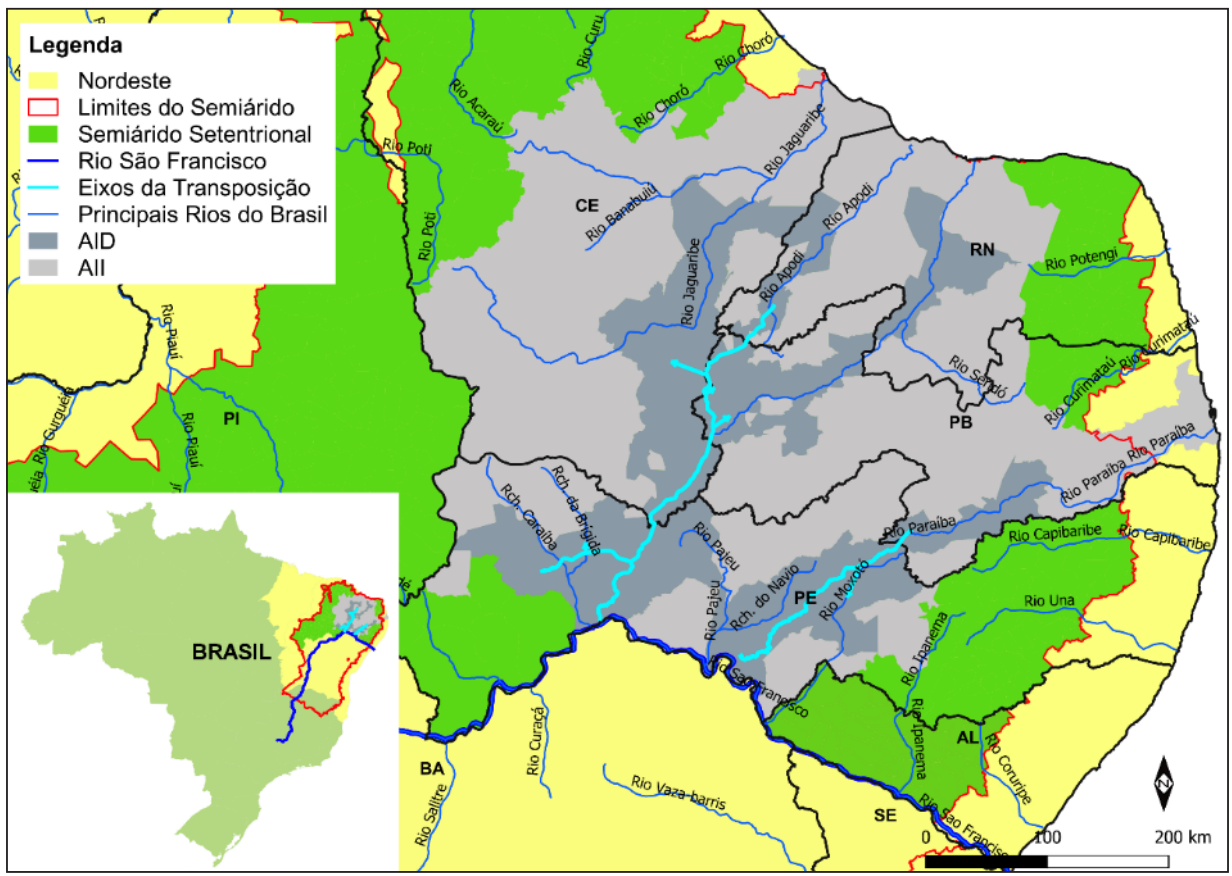

FIGURA 1 - Localização dos eixos e das áreas de influência do Projeto de Transposição.

FONTE: Viana (2014), malha disponibilizada pelo IBGE e pelo Comitê de Bacias Hidrográficas do Rio São Francisco (CBHRSF). 
A Área de Influência Direta (AID) é a área mais diretamente relacionada às obras da transposição e é composta por 86 municípios. Por outro lado, a Área de Influência Indireta (AII) possui 307 municípios. Foi registrado que a AID possuía um total de 1,6 milhão de habitantes, com $62 \%$ residindo em áreas classificadas como urbanas e 38\% (636.296) em área rural. Na AII, registrou-se 6,2 milhões de habitantes, com $71 \%$ residindo em áreas urbanas e $29 \%$ no rural. Assim, ao todo a região delimitada pelo EIA-RIMA considera 393 municípios onde residiam 7,8 milhões de habitantes, $69 \%$ destes habitando no meio urbano. Trata-se de mais da metade da população da região Nordeste.

Como o objetivo é verificar os efeitos da mobilidade populacional sobre a vulnerabilidade sociodemográfica nos espaços urbanos das áreas de influência do Projeto de Transposição, a AID foi selecionada por entendermos como a mais adequada para o objetivo dos efeitos mais imediatos sobre a dinâmica populacional. Assim, a Figura 2 e a Tabela 1 trazem informações detalhadas da AID.

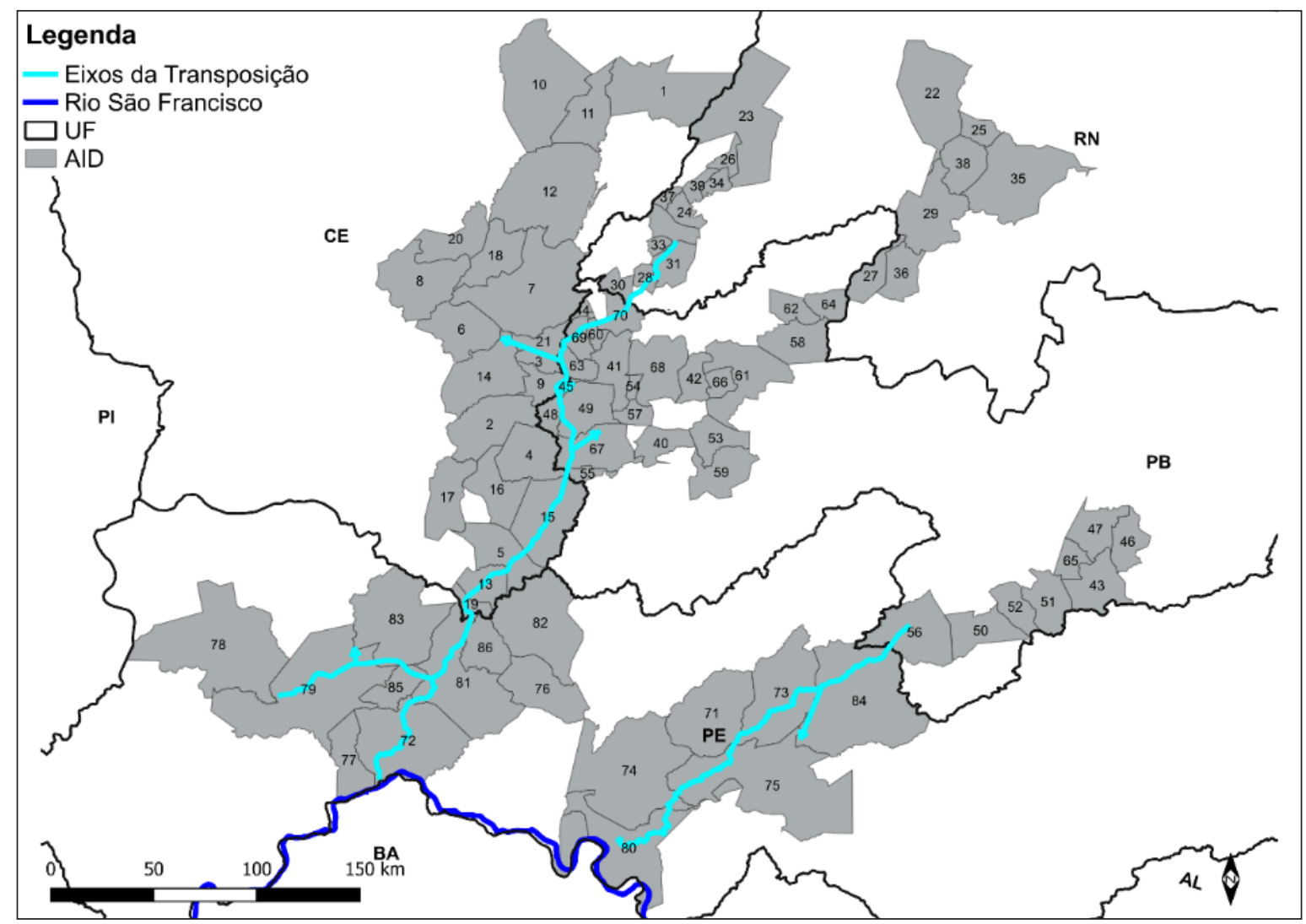

FIGURA 2 - Localização dos municípios que compõem a Área de Influência Direta (AID).

FONTE: Viana (2014), malha disponibilizada pelo IBGE e pelo Comitê de Bacias Hidrográficas do Rio São Francisco (CBHRSF). 
TABELA 1 - Lista de identificação (ID) dos municípios da AID do Projeto de Transposição, segundo Unidades da Federação (UF).

\begin{tabular}{|c|c|c|c|c|c|c|c|c|c|c|c|}
\hline ID & Município & $\mathbf{U F}$ & ID & Município & UF & ID & Município & UF & ID & Município & $\mathbf{U F}$ \\
\hline 1 & Alto Santo & $\mathrm{CE}$ & 23 & Apodi & RN & 45 & Bom Jesus & PB & 67 & $\begin{array}{l}\text { São José de } \\
\text { Piranhas }\end{array}$ & PB \\
\hline 2 & Aurora & $\mathrm{CE}$ & 24 & $\begin{array}{l}\text { Francisco } \\
\text { Dantas }\end{array}$ & $\mathrm{RN}$ & 46 & Boqueirão & PB & 68 & Sousa & PB \\
\hline 3 & Baixio & $\mathrm{CE}$ & 25 & Itajá & $\mathrm{RN}$ & 47 & Cabaceiras & PB & 69 & Triunfo & PB \\
\hline 4 & Barro & $\mathrm{CE}$ & 26 & Itaú & $\mathrm{RN}$ & 48 & $\begin{array}{l}\text { Cachoeira dos } \\
\text { Índios }\end{array}$ & PB & 70 & Uiraúna & PB \\
\hline 5 & Brejo Santo & $\mathrm{CE}$ & 27 & $\begin{array}{l}\text { Jardim De } \\
\text { Piranhas }\end{array}$ & $\mathrm{RN}$ & 49 & Cajazeiras & PB & 71 & Betânia & $\mathrm{PE}$ \\
\hline 6 & Cedro & $\mathrm{CE}$ & 28 & José da Penha & $\mathrm{RN}$ & 50 & Camalaú & $\mathrm{PB}$ & 72 & Cabrobó & $\mathrm{PE}$ \\
\hline 7 & Icó & $\mathrm{CE}$ & 29 & Jucurutu & $\mathrm{RN}$ & 51 & Caraíbas & PB & 73 & Custódia & $\mathrm{PE}$ \\
\hline 8 & Iguatu & $\mathrm{CE}$ & 30 & Luiz Gomes & $\mathrm{RN}$ & 52 & Congo & PB & 74 & Floresta & $\mathrm{PE}$ \\
\hline 9 & Ipaumirim & $\mathrm{CE}$ & 31 & Marcelino Vieira & $\mathrm{RN}$ & 53 & Coremas & PB & 75 & Ibimirim & $\mathrm{PE}$ \\
\hline 10 & Jaguaretama & $\mathrm{CE}$ & 32 & Pau dos Ferros & $\mathrm{RN}$ & 54 & Marizópoles & PB & 76 & Mirandiba & PE \\
\hline 11 & Jaguaribara & $\mathrm{CE}$ & 33 & $\begin{array}{c}\text { Rafael } \\
\text { Fernandes }\end{array}$ & $\mathrm{RN}$ & 55 & Monte Horebe & PB & 77 & Orocó & $\mathrm{PE}$ \\
\hline 12 & Jaguaribe & $\mathrm{CE}$ & 34 & Riacho da Cruz & $\mathrm{RN}$ & 56 & Monteiro & PB & 78 & Ouricuri & $\mathrm{PE}$ \\
\hline 13 & Jati & $\mathrm{CE}$ & 35 & $\begin{array}{l}\text { Santana do } \\
\text { Matos }\end{array}$ & $\mathrm{RN}$ & 57 & Nazarezinho & PB & 79 & Parnamirim & $\mathrm{PE}$ \\
\hline 14 & $\begin{array}{l}\text { Lavras da } \\
\text { Mangabeira }\end{array}$ & $\mathrm{CE}$ & 36 & São Fernando & $\mathrm{RN}$ & 58 & Paulista & PB & 80 & Petrolândia & $\mathrm{PE}$ \\
\hline 15 & Mauriti & $\mathrm{CE}$ & 37 & $\begin{array}{c}\text { São Francisco do } \\
\text { Oeste }\end{array}$ & $\mathrm{RN}$ & 59 & Piancó & PB & 81 & Salgueiro & $\mathrm{PE}$ \\
\hline 16 & Milagres & $\mathrm{CE}$ & 38 & São Rafael & $\mathrm{RN}$ & 60 & $\begin{array}{c}\text { Poço de José de } \\
\text { Moura }\end{array}$ & PB & 82 & $\begin{array}{l}\text { São José do } \\
\text { Belmonte }\end{array}$ & PE \\
\hline 17 & Missão Velha & $\mathrm{CE}$ & 39 & $\begin{array}{l}\text { Taboleiro } \\
\text { Grande }\end{array}$ & $\mathrm{PB}$ & 61 & Pombal & PB & 83 & Serrita & PE \\
\hline 18 & Orós & $\mathrm{CE}$ & 40 & Aguiar & $\mathrm{PB}$ & 62 & $\begin{array}{l}\text { Riacho dos } \\
\text { Cavalos }\end{array}$ & PB & 84 & Sertânia & $\mathrm{PE}$ \\
\hline 19 & Penaforte & $\mathrm{CE}$ & 41 & $\begin{array}{c}\text { São João do Rio } \\
\text { do Peixe }\end{array}$ & $\mathrm{PB}$ & 63 & Santa Helena & PB & 85 & Terra Nova & PE \\
\hline 20 & Quixelô & $\mathrm{CE}$ & 42 & Aparecida & $\mathrm{PB}$ & 64 & São Bento & PB & 86 & Verdejante & PE \\
\hline 21 & Umari & $\mathrm{CE}$ & 43 & $\begin{array}{l}\text { Barra de São } \\
\text { Miguel }\end{array}$ & $\mathrm{PB}$ & 65 & $\begin{array}{l}\text { São Domingos } \\
\text { do Cariri }\end{array}$ & PB & & & \\
\hline 22 & Açu & $\mathrm{RN}$ & 44 & $\begin{array}{c}\text { Bernardino } \\
\text { Batista }\end{array}$ & $\mathrm{PB}$ & 66 & São Domingos & PB & & & \\
\hline
\end{tabular}

FONTE: Viana (2014), malha disponibilizada pelo IBGE e pelo Comitê de Bacias Hidrográficas do Rio São Francisco (CBHRSF). 
Para avaliar a vulnerabilidade, desenvolvemos um Índice de Vulnerabilidade Sociodemográfica (IVSD) para os municípios selecionados. O índice proposto é qualitativo e quantitativo, o que faz dele flexível e por isso podem ser incorporados outros elementos que permitam qualificar da melhor maneira as condições de vida da população e dos lugares, ao mesmo tempo em que se avalia a vulnerabilidade no contexto da mobilidade populacional na AID da transposição. Ou seja, procedeu-se à construção de um indicador de vulnerabilidade para dois cenários distintos: o primeiro é o efetivamente observado a partir da análise dos dados dos municípios da AID. O cenário de comparação, contrafactual, contém os mesmos municípios, mas a partir da exclusão da população migrante. Assim, procedeu-se à comparação do índice de vulnerabilidade para estes dois cenários no intuito de avaliar o papel da mobilidade nesse índice.

Neste sentido, o desafio foi elaborar um índice sintético de vulnerabilidade, o que não é uma tarefa fácil, já que se trata de um conceito multidimensional e multicausal, o que leva à necessidade de se mesclar metodologias de naturezas quantitativas e qualitativas (Prieto, 2008). Pensando nisso, adotou-se a proposta de Kaztman (1999) que incorporou, em termos de ativos, características que podem determinar as condições de bem-estar dos atores e dos lugares. Estes ativos (presentes nas dimensões capital físico, capital humano e capital social) possuem um conjunto de atributos considerados necessários para o aproveitamento da estrutura de oportunidades existentes, que sem esses atributos colocaria os atores e os lugares em situação de vulnerabilidade. Já pela ótica quantitativa, adota-se como base o índice de vulnerabilidade social desenvolvido em Cunha et al. (2006) para o município de Campinas, que utilizou as áreas de ponderação (recortes intramunicipais dos dados amostrais do Censo Demográfico) deste município e também considerou as dimensões propostas por Kaztman (1999). Também se tomou como referência outras investigações desenvolvidas especialmente por pesquisadores do Centro Latinoamericano y Caribeño de Demografía (CELADE) (Rodríguez, 2000, 2001; Busso, 2002, 2005; Melo, 2005; Rodríguez, 2006; Gonzáles, 2007; Prieto, 2008) para seleção dos indicadores. A principal fonte de dados aqui utilizada foi o Censo Demográfico de 2010.

Dito isto, utilizamos a técnica de Análise de Componente Principal (ACP) para o agrupamento dos indicadores sociodemográficos em fatores, para facilitar a identificação e interpretação das relações estruturais entre os indicadores que, de outra forma, poderiam passar despercebidas ao considerar um número muito grande deles (Fávero et al., 2009).

Para facilitar a análise das cargas fatoriais, foi utilizado o método Varimax, que é um artifício geométrico que permite uma melhor distribuição das cargas fatoriais em relação a cada componente selecionada. Dessa maneira, esse método assume que os fatores são independentes entre si e minimiza o número de indicadores com altas cargas fatoriais em um conjunto específico de indicadores (Macedo \& Bassani, 2010). Assim, foi possível selecionar os indicadores para cada dimensão de ativos, em capital físico, capital humano e capital social, reduzindo a chance de que diferentes indicadores estivessem se sobrepondo.

O procedimento de cálculo da ACP e critérios de escolha dos indicadores para cada dimensão, com base na literatura (Fávero et al., 2009; Macedo \& Bassani, 2010), se deu da seguinte maneira: 
i) geração da matriz de correlações com suas correspondentes probabilidades de significância;

ii) geração da matriz anti-imagem das correlações, o que permite verificar as medidas de adequação da amostra Kaiser-MeyerOlkin $^{2}$ (KMO);

ii.i) acima de 0,600 para a matriz como um todo; $\mathrm{e}$

ii.ii) acima de 0,500 para cada indicador, sendo eliminados aqueles abaixo disso, exceto quando as comunalidades forem altas.

iii) Teste Bartlett ${ }^{3}$ para verificar se a matriz de correlações é apropriada para a aplicação da ACP;

iii.i) p-valor menor que 0,5 .

iv) Variância acumulada superior a 50\%.

Os procedimentos foram desenvolvidos com o uso do SPSS (Statistical Package for the Social Science) e, tendo em mente os requisitos estatísticos descritos anteriormente, foram geradas as cargas fatoriais e o número de fatores para cada dimensão, bem como as suas participações na variância explicada.

Tendo em vista que a principal hipótese desta pesquisa é verificar o quanto a mobilidade populacional pode afetar a vulnerabilidade sociodemográfica nos espaços urbanos da AID, foi preciso considerar dois cenários. Um primeiro cenário considerou toda a população residente no meio urbano (cenário observado) existente no Censo
Demográfico de 2010. E como opção contrafactual, o segundo cenário, onde não se considerou a população migrante que, hipoteticamente, julgamos intensificar a vulnerabilidade sociodemográfica das áreas de influência. Dessa forma, esperamos obter um parâmetro de comparação onde avaliamos em que medida o perfil dos migrantes pode ou não ter contribuído com a vulnerabilidade sociodemográfica da AID.

Antes de selecionar os indicadores para cada dimensão, definimos a população que julgamos trazer maiores desafios à AID. Dessa maneira, para a mensuração da mobilidade populacional atraída pelo Projeto de Transposição, além do recorte espacial específico, foi adotado o quesito censitário de "última etapa", comumente utilizado nos estudos de migração (Rigotti, 1999; Queiroz, 2013), para captar a população migrante com menos de quatro anos de residência - considerando o tempo de início da obra da transposição, que foi em 2007, e a periodicidade da base de dados disponível, que é o Censo Demográfico de 2010. No que diz respeito aos deslocamentos pendulares, por motivo de trabalho e/ou estudo, Costa (2020) verificou que ao menos $36 \%$ destes migrantes praticavam deslocamentos diários na AID. Dessa maneira, pode-se tomar a população migrante residente na AID com menos de quatro anos como representante da mobilidade populacional como um todo. Diferente do conceito de migração, o da mobilidade populacional não se limita à mudança permanente ou semipermanente de residência dos indivíduos, pois também considera os movimentos populacionais de curta duração

\footnotetext{
${ }^{2} \mathrm{O}$ valor aceitável para este teste tem que ser superior a 0,600, o que indica alta correlação entre os indicadores e correlações parciais baixas.

${ }^{3}$ Este teste verifica a hipótese nula de que a matriz de correlação é uma matriz identidade; tendo p-valor menor que 0,5 esta hipótese não é aceita, o que significa dizer que existe correlação entre os indicadores da componente.
} 
que têm se intensificado, seja por questões sociais, econômicas, políticas ou ambientais, e que também afetam as migrações (Hogan, 2005). Assim, por ser um conceito mais abrangente, o termo "mobilidade populacional" é o que será utilizado neste estudo.

Dito isto, a partir da análise dos cenários propostos será possível visualizar se as características multidimensionais da população migrante, com menos de quatro anos de residência, alteraram o quadro da vulnerabilidade sociodemográfica dos municípios que compõem a AID do Projeto de Transposição. Para o cenário observado (Cenário 1), as dimensões com seus fatores e respectivas cargas fatoriais, assim como o percentual das variâncias explicadas e a interpretação de cada fator, encontram-se nas Tabelas 2, 3 e 4. As dimensões, como já mencionadas, são três:

I) Capital Físico: inclui ativos relativos aos meios de vida, como as condições de habitação, acesso a bens duráveis, acesso a serviços básicos de infraestrutura, condição financeira da família, e de mobilidade diária;

II) Capital Humano: inclui como ativo principal o trabalho, sendo considerados os ativos que agregam valor a ele, como as condições de educação, saúde e composição etária que podem implicar em maior ou menor capacidade física para o trabalho;

III) Capital Social: inclui ativos relacionados às redes de contatos, reciprocidade, confiança e acesso à informação entre as pessoas. Como aproximação dessas redes, foram adotados ativos que remetem à formação e ao rendimento familiar; à inserção e instabilidade no mercado de trabalho; e ao acesso à proteção social e assistencial. Uma das principais limitações dessa dimensão é a ausência de elementos, no Censo Demográfico, que expressassem de forma mais evidente aquelas redes.

As dimensões apresentadas trazem elementos que têm relação com as condições de vulnerabilidade social da população residente na AID do Projeto de Transposição, as quais estão vinculadas às condições de funcionamento do mercado, à insegurança no Estado e ao debilitamento da instituição primordial, a família. Isso tudo, segundo Kaztman (1999), se traduz em uma fonte importante para se analisar a vulnerabilidade social. Então, seguindo os procedimentos e questões anteriormente mencionados, foram determinados os indicadores para cada fator, formados por aqueles com as cargas fatoriais mais altas, que se encontram destacados em vermelho nas tabelas que se seguem. As discussões aqui apresentadas detalham a seleção dos indicadores para o índice a partir da interpretação dos resultados da análise ACP. Ou seja, as Tabelas 2, 3 e 4 e as análises a seguir apresentam os resultados que justificam a inclusão ou não de determinado indicador a partir da evidência de que sua contribuição como fator explicativo é válida estatisticamente.

Para a dimensão Capital Físico (CF) (Tabela 2), considerando os critérios estabelecidos, o que se verificou para o primeiro fator foi uma combinação de indicadores referentes às condições de moradia, sendo que alguns apresentaram altas correlações positivas (densidade de moradores por dormitório acima de duas pessoas, $\%$ de pessoas morando em domicílios com dois ou mais banheiros, \% de pessoas morando em domicílios alugados e $\%$ de pessoas morando em domicílio próprio em aquisição) e outras correlações negativas (\% de pessoas morando em domicílio tipo casa, \% de chefes de família (ou 
TABELA 2 - Dimensão Capital Físico e fatores de vulnerabilidade, segundo indicadores, para o cenário 1 (Observado) - AID - 2010.

\begin{tabular}{|c|c|c|c|c|}
\hline \multirow{2}{*}{$\begin{array}{c}\text { Capital Físico } \\
\text { Indicadores } \\
\end{array}$} & \multicolumn{4}{|c|}{ Fatores } \\
\hline & 1 & 2 & 3 & 4 \\
\hline 1. Densidade de moradores por dormitório acima de duas pessoas & 0,800 & 0,285 & 0,156 & $-0,177$ \\
\hline 3. \% de pessoas morando em domicílios "alugados" & 0,728 & 0,083 & 0,334 & 0,108 \\
\hline 4. \% de pessoas morando em domicílio "próprio em aquisição" & 0,652 & 0,217 & $-0,223$ & 0,021 \\
\hline 7. \% de pessoas morando em domicílios sem acesso a telefone/celular & $-0,559$ & 0,395 & 0,091 & $-0,145$ \\
\hline 8. \% de pessoas morando em domicílios sem banheiro & $-0,108$ & 0,783 & $-0,271$ & $-0,065$ \\
\hline 9. Densidade de moradores por cômodo & 0,280 & 0,729 & 0,181 & $-0,052$ \\
\hline 10. $\%$ de pessoas morando em domicílios sem coleta adequada de lixo & $-0,008$ & 0,675 & 0,082 & 0,304 \\
\hline 13. \% de pessoas morando em domicílios sem geladeira & $-0,234$ & 0,541 & 0,595 & 0,001 \\
\hline 14. \% de pessoas morando em domicílios sem rede geral de água & 0,009 & 0,223 & 0,121 & 0,821 \\
\hline 15. \% de pessoas morando em domicílio tipo "cômodo" & 0,050 & 0,144 & 0,272 & $-0,500$ \\
\hline \multirow[t]{2}{*}{ \% da variância explicada } & 22,02 & 16,58 & 13,16 & 9,03 \\
\hline & $\begin{array}{c}\text { Condição } \\
\text { da ocupação } \\
\text { domiciliar }\end{array}$ & $\begin{array}{c}\text { Deficiência na } \\
\text { infraestrutura } \\
\text { domiciliar }\end{array}$ & $\begin{array}{c}\text { Condição } \\
\text { socioeconômica } \\
\text { da mobilidade } \\
\text { diária }\end{array}$ & $\begin{array}{c}\text { Carência na } \\
\text { infraestrutura } \\
\text { hídrica }\end{array}$ \\
\hline
\end{tabular}

FONTE: Resultados da ACP.

individual) com renda de 0 a $1 / 2$ salário mínimo e $\%$ de pessoas morando em domicílios sem acesso a telefone/celular). Dessa maneira, o primeiro fator foi nomeado "condição da ocupação domiciliar", que se assemelha às ocupações urbanas.

$\mathrm{O}$ fator 2 traz um conjunto de indicadores que remetem a condições inapropriadas de habitação: \% de pessoas morando em domicílios sem banheiro, densidade de moradores por cômodo e $\%$ de pessoas morando em domicílios sem coleta adequada de lixo. Por isso, foi nomeado como "deficiência na infraestrutura domiciliar".

Os indicadores com as maiores cargas fatoriais que formaram o fator 3 foram três: $\%$ de pessoas morando em domicílios sem rede geral de esgoto, $\%$ de pessoas que vivem em domicílios com renda per capita inferior a meio salário mínimo e que gastam mais de uma hora até o trabalho no total de pessoas ocupadas, e que retornam diariamente do trabalho, e \% de pessoas morando em domicílios sem geladeira. A correlação estabelecida entre os indicadores sugere que a mobilidade diária de uma população tão específica, isto é, por ser vulnerável à pobreza e percorrer longas distâncias diariamente, tem alta correlação com a baixa aquisição de bens duráveis. Dessa maneira, a denominação deste fator foi "condição socioeconômica da mobilidade diária". 
Por fim, o fator 4 , formado pelos indicadores $\%$ de pessoas morando em domicílios sem rede geral de água e \% de pessoas morando em domicílio tipo cômodo, ressalta uma situação precária no abastecimento hídrico na AID, visto que a primeira variável registrou alta correlação positiva com o fator e a segunda alta correlação negativa. Por isso, este fator foi denominado "carência na infraestrutura hídrica".

No que concerne à dimensão Capital Humano (CH) (Tabela 3), o primeiro fator foi contemplado por três indicadores: \% de pessoas com 18 anos ou mais sem fundamental completo, taxa de analfabetismo de pessoas com 15 anos ou mais de idade e $\%$ de chefes de família (ou individuais) com menos de 4 anos de escolaridade. Este fator retrata, portanto, a fragilidade do capital humano desta área de influência. Dada a alta correlação positiva destes indicadores com este fator, a nomeação sugerida foi "carência de capital humano".
$\mathrm{O}$ fator 2 , formado pelos indicadores $\%$ de pessoas com alguma dificuldade de ouvir, ver, caminhar ou subir escadas, Índice de Envelhecimento e \% de mulheres de 10 a 17 anos de idade que tiveram filhos, remete às condições de saúde da população com pano de fundo do gradual envelhecimento demográfico devido às altas cargas positivas dos dois primeiros indicadores deste fator. A nomeação sugerida foi "condição de saúde crítica".

Quanto ao fator 3, as maiores cargas fatoriais e positivas correspondem aos indicadores \% de mulheres chefes de família sem ensino fundamental completo e com pelo menos um filho com menos de três anos e Razão de Dependência. A correlação destes dois indicadores remete ao que pode ser denominado de "capital humano feminino precário". Por fim, o quarto fator foi contemplado apenas pelo indicador \% de jovens (15 a 24 anos) que não estudam, não trabalham e são vulneráveis

TABELA 3 - Dimensão Capital Humano e fatores de vulnerabilidade, segundo indicadores, para o cenário 1 (Observado) - AID - 2010.

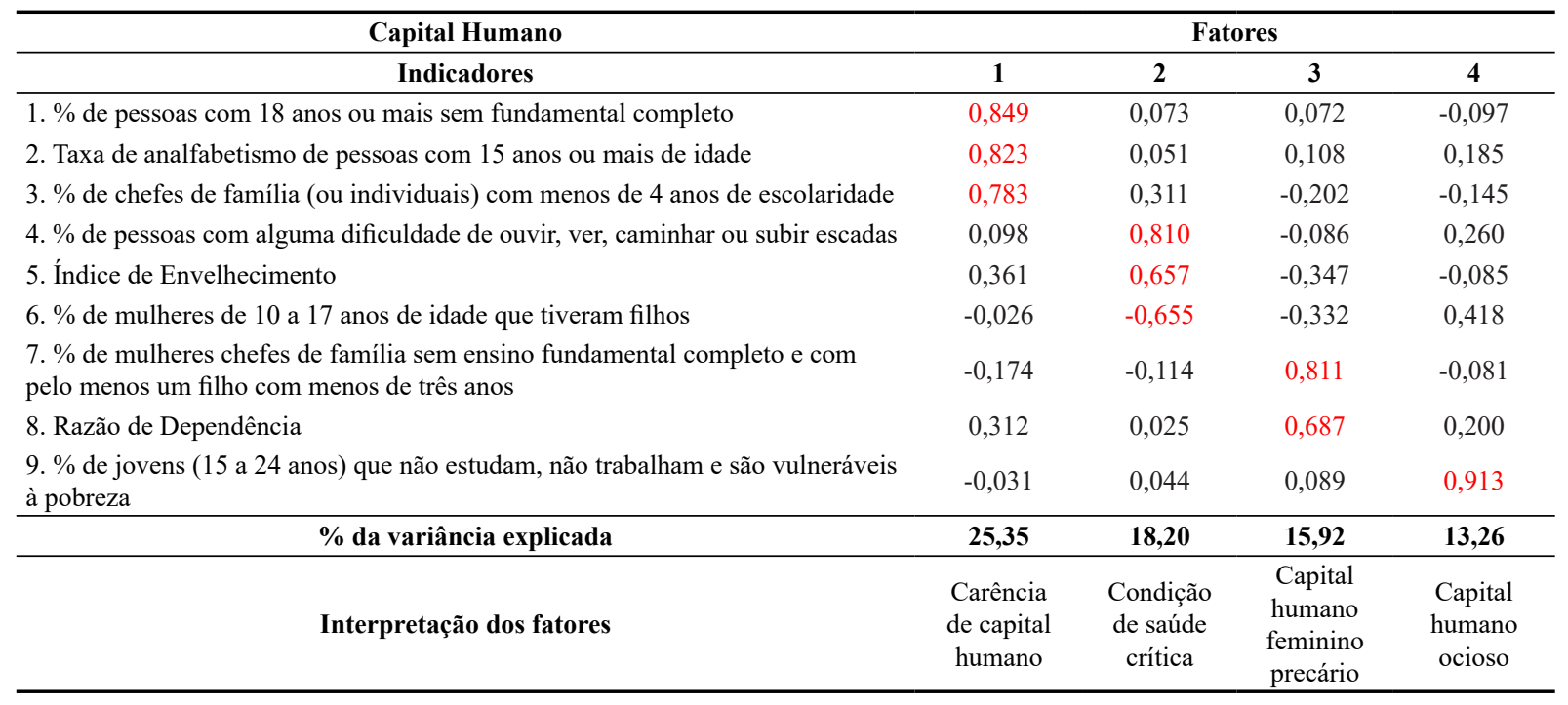

FONTE: Resultados da ACP. 
à pobreza, sugerindo a seguinte nomeação: "capital humano ocioso".

Por fim, no que tange ao Capital Social (CS) (Tabela 4), foram registrados três fatores nesta dimensão. $\mathrm{O}$ fator 1 foi estabelecido pela composição de quatro indicadores: \% famílias com renda per capita até $1 / 2$ salário mínimo, tamanho médio da família 01 (principal), \% de famílias unipessoais femininas com rendimento até $1 / 2$ salário mínimo e $\%$ de crianças que não frequentam escola ou creche, que pode ser nomeado de "condição familiar precária", visto que as cargas fatoriais foram altas e positivas.

$\mathrm{O}$ fator 2 foi composto pelos indicadores $\% \mathrm{de}$ pessoas com 10 anos ou mais de idade ocupadas em atividades agrícolas e $\%$ de pessoas que recebem rendimento habitual mensal do Programa Bolsa Família (PBF) ou do Programa de Erradicação do Trabalho Infantil (PETI), o que levou a dar a nomeação de "condição assistencial". Essa com- posição remete a uma forma de estratégia familiar, já que essa ocupação é uma das mais vulneráveis, haja vista os longos períodos de seca na região; e o auxílio dado pelo governo possibilita uma melhor qualidade de vida à população nesta condição.

Por fim, o fator 3 foi contemplado com três indicadores: taxa de desocupação da população de 18 anos ou mais de idade, taxa de atividade das pessoas de 10 a 14 anos de idade e $\%$ de mulheres responsáveis pelo domicílio com rendimento inferior $1 \frac{2}{2}$ salário mínimo, os quais sugerem a seguinte nomeação ao referido fator: "condição ocupacional precária”.

As Tabelas 5, 6 e 7, por sua vez, apresentam as correlações (cargas) dos indicadores respectivamente para cada dimensão considerando o cenário 2 (alternativo). Com a saída da população migrante, viu-se um novo rearranjo dos indicadores em cada fator, assim como a mudança de alguns para outros fatores. Por exemplo, os indicadores \% de chefes de

TABELA 4 - Dimensão Capital Social e fatores de vulnerabilidade, segundo indicadores, para o cenário 1 (Observado) - AID - 2010.

\begin{tabular}{|c|c|c|c|}
\hline \multirow{2}{*}{$\begin{array}{c}\text { Capital Social } \\
\text { Indicadores }\end{array}$} & \multicolumn{3}{|c|}{ Fatores } \\
\hline & 1 & 2 & 3 \\
\hline 1. $\%$ famílias com renda per capita até $1 / 2 \mathrm{SM}$ & 0,812 & 0,060 & $-0,075$ \\
\hline 3. \% de famílias unipessoais femininas com rendimento até $1 / 2 \mathrm{SM}$ & 0,610 & $-0,036$ & 0,091 \\
\hline 4. \% de crianças que não frequentam escola ou creche & 0,511 & $-0,265$ & $-0,327$ \\
\hline 7. Taxa de desocupação da população de 18 anos ou mais de idade & 0,067 & 0,056 & 0,716 \\
\hline 8. Taxa de atividade das pessoas de 10 a 14 anos de idade & 0,318 & 0,088 & $-0,656$ \\
\hline 9. \% de mulheres responsáveis pelo domicílio com rendimento inferior a $1 / 2 \mathrm{SM}$. & 0,384 & 0,154 & 0,577 \\
\hline \% da variância explicada & 24,08 & 16,21 & 15,69 \\
\hline
\end{tabular}

FONTE: Resultados da ACP. 
família (ou individual) com renda de 0 a $1 \frac{1}{2}$ salário mínimo e \% de pessoas morando em domicílios sem acesso a telefone/celular, do primeiro fator da dimensão CF (Tabela 5), passaram a se enquadrar no segundo fator desta dimensão. Contudo, a saída dos referidos indicadores não compromete a interpretação do primeiro fator, nem a do segundo quando comparado ao cenário observado (Tabela 2). A interpretação dos fatores 3 e 4 também não se altera porque aqueles indicadores de maior carga positiva ainda permaneceram, embora também tenham se observado algumas mudanças.

TABELA 5 - Dimensão Capital Físico e fatores de vulnerabilidade, segundo indicadores, para o cenário 2 (Alternativo) - AID - 2010.

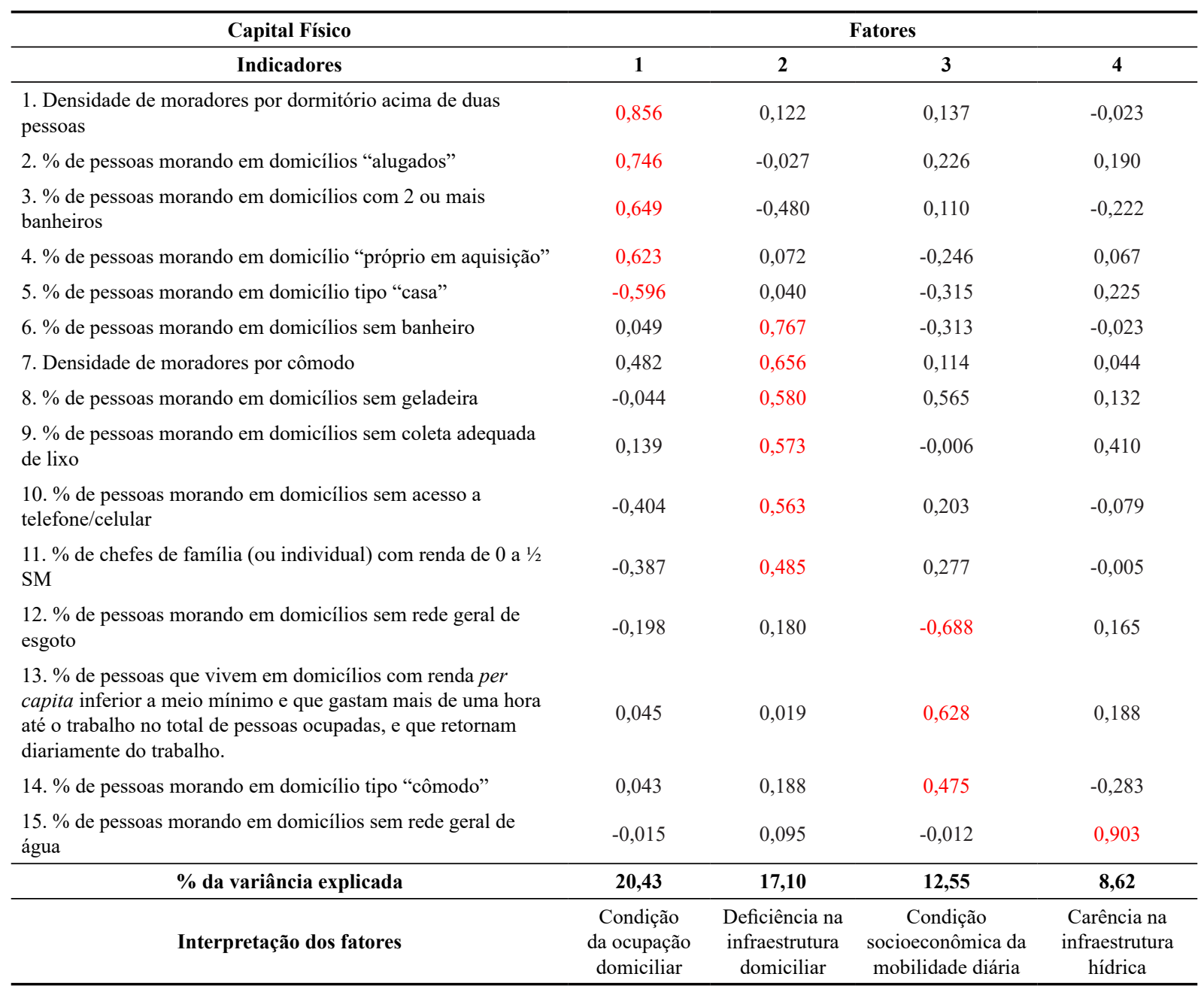

FONTE: Resultados da ACP. 
As mudanças mais significativas foram verificadas nas dimensões do Capital Humano (Tabela 6) e Capital Social (Tabela 7). No Capital Humano houve a exclusão de um fator, contabilizando desta forma três fatores com a mesma interpretação sugerida no cenário observado. Já na dimensão Capital
Social o número de fatores foi o mesmo registrado no cenário 1 , entretanto, os dois últimos fatores receberam nomenclatura diferente. $\mathrm{O}$ fator 2 , formado pelos indicadores taxa de atividade das pessoas de 10 a 14 anos de idade e \% de crianças que não frequentam escola ou creche, foi denominado como

TABELA 6 - Dimensão Capital Humano e fatores de vulnerabilidade, segundo indicadores, para o cenário 2 (Alternativo) - AID - 2010.

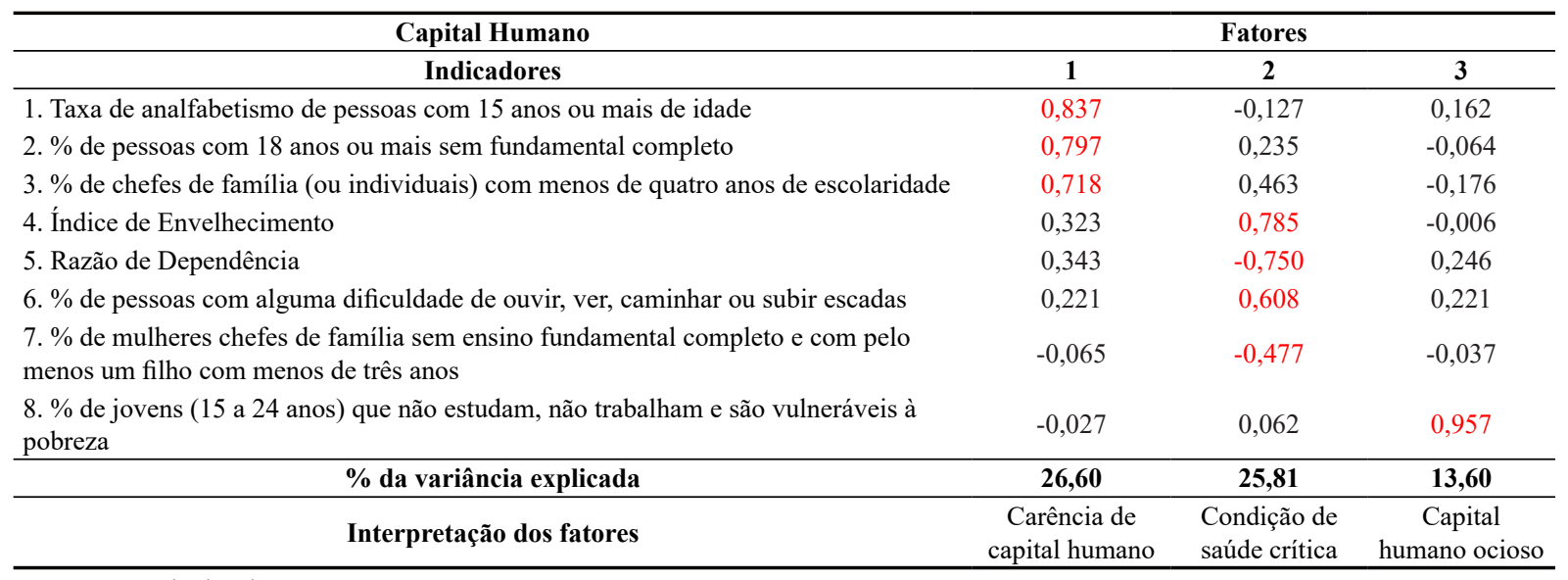

FONTE: Resultados da ACP.

NOTA: Os indicadores que não estão nesta tabela, mas que estavam no anterior, foram excluídos porque não seguiram os critérios estabelecidos inicialmente para a ACP.

TABELA 7 - Dimensão Capital Social e fatores de vulnerabilidade, segundo indicadores, para o cenário 2 (Alternativo) - AID - 2010.

\begin{tabular}{|c|c|c|c|}
\hline \multirow{2}{*}{$\begin{array}{c}\text { Capital Social } \\
\text { Indicadores }\end{array}$} & \multicolumn{3}{|c|}{ Fatores } \\
\hline & 1 & 2 & 3 \\
\hline 1. Tamanho médio da família 01 (principal) & 0,734 & 0,164 & 0,140 \\
\hline 2. $\% \%$ famílias com renda per capita até $1 / 2 \mathrm{SM}$ & 0,729 & 0,346 & 0,268 \\
\hline 3. \% de pessoas sendo agregados da família & 0,690 & $-0,182$ & $-0,228$ \\
\hline 4. Taxa de atividade das pessoas de 10 a 14 anos de idade & $-0,087$ & 0,814 & 0,045 \\
\hline 5. \% de crianças que não frequentam escola ou creche & 0,279 & 0,685 & $-0,100$ \\
\hline 7. \% de famílias unipessoais femininas com rendimento até $1 / 2 \mathrm{SM}$ & 0,295 & 0,025 & 0,590 \\
\hline \% da variância explicada & 24,92 & 18,80 & 16,73 \\
\hline Interpretação dos fatores & $\begin{array}{c}\text { Condição } \\
\text { familiar precária }\end{array}$ & $\begin{array}{c}\text { Condição } \\
\text { assistencial } \\
\text { precária }\end{array}$ & $\begin{array}{l}\text { Condição } \\
\text { de proteção } \\
\text { assistencial }\end{array}$ \\
\hline
\end{tabular}

FONTE: Resultados da ACP.

NOTA: Os indicadores que não estão nesta tabela, mas que estavam no anterior, foram excluídos porque não seguiram os critérios estabelecidos inicialmente para a ACP. 
“condição assistencial precária", já que se refere a uma forte correlação entre crianças que trabalham e não frequentam escola ou creche. Quanto ao terceiro fator, composto pelos indicadores $\%$ de pessoas que recebem rendimento habitual mensal do PBF ou PETI e \% de famílias unipessoais femininas com rendimento até $1 / 2$ salário mínimo, foi sugerida a seguinte interpretação para esta correlação: "condição de proteção assistencial".

Portanto, foram apresentados os resultados da ACP para ambos os cenários da vulnerabilidade sociodemográfica, os quais expõem os conjuntos ajustados de indicadores para interpretar da melhor maneira as desvantagens sociodemográficas presentes na AID do Projeto de Transposição no sertão nordestino.

Por fim, feita a análise dos fatores, foi possível desenvolver o índice de vulnerabilidade sociodemográfica para cada unidade de análise (municípios) da AID. Antes disso, atribuímos os fatores de cada dimensão a cada município e calculamos a média ponderada dos escores utilizando os autovalores (variância) dos fatores de cada dimensão para cada município. Para o cálculo da média, foi utilizada a fórmula seguinte (1):

$$
E M P_{i}=\frac{\sum F A T^{*} P}{\sum P}
$$

Onde,

$\mathrm{EMP}_{\mathrm{i}}=$ Escore Médio Ponderado para o município i;

FAT $=$ Carga fatorial;

$\mathrm{P}=$ Peso (\% da variância explicada).

É pertinente destacar que cada dimensão, em cada cenário, apresentou seu percentual de variância que explica cada fator, isto é, o quanto cada fator explica a variabilidade dos dados originais. Então, foi a partir das variâncias que se deram os devidos pesos de cada fator às unidades de análise.

Assim, a partir dos Escores Médios Ponderados para cada município, foi criado o Índice de Vulnerabilidade Sociodemográfica para cada dimensão (Capital Físico-CF, Capital Humano-CH e Capital Social-CS). O cálculo matemático para o referido procedimento encontra-se a seguir, com base em Macedo \& Bassani (2010):

$$
I V S D x_{i}=\frac{\left(E M P_{i}-E M P_{\text {min }}\right)}{\left(E M P_{\text {max }}-E M P_{\text {min }}\right)}
$$

Onde,

$I V S D x_{i}^{=}$Índice de Vulnerabilidade Sociodemográfica da dimensão x para o município i

$E M P_{i}=$ Escore médio Ponderado da dimensão $\mathrm{x}$ do município i

$E M P_{\min }=$ Escore médio mínimo Ponderado da dimensão $\mathrm{x}$

$E M P_{\text {máx }}=$ Escore médio máximo Ponderado da dimensão $\mathrm{x}$

Portanto, o IVSD pode variar entre 0 e 1 , sendo que, quanto mais próximo de 1 , maior o grau de vulnerabilidade do município (Tabela 8). Assim, o IVSD fornece um gradiente de vulnerabilidade para os espaços urbanos dentro da AID, facilitando, dessa maneira, a visualização das heterogeneidades espaciais. É válido salientar que para o tratamento espacial para a construção de mapas temáticos e de localização foi utilizado o programa QGIS versão 3.4 .

TABELA 8 - Classificação do IVSD.

\begin{tabular}{cccc}
\hline Baixo & Médio Baixo & Médio Alto & Alto \\
\hline 0,00 a 0,25 & $\mathbf{0 , 2 5}$ a $\mathbf{0 , 5 0}$ & 0,50 a 0,75 & $\mathbf{0 , 7 5}$ a $\mathbf{1 , 0 0}$ \\
\hline
\end{tabular}




\section{Mobilidade Populacional vs}

\section{Vulnerabilidade Sociodemográfica: cenários do IVSD na AID}

A migração é uma das componentes demográficas de maior relação com as mudanças que ocorreram na população nordestina. A distribuição espacial observada, especialmente a partir dos anos 1980, tanto da população quanto das atividades produtivas, obedece a fatores estruturais e históricos que definem a situação atual e a inércia que influenciará a região por mais outras décadas à frente.

Segundo o EIA-RIMA, realizado em 2004, os deslocamentos populacionais são tidos como um dos principais impactos demográficos do Projeto de Transposição em função da combinação entre os deslocamentos populacionais dos espaços rurais, para dar passagem aos eixos, e a mobilização de mão de obra, para o estágio de instalação dos eixos ou canais. Os municípios com previsão de impacto relativamente alto foram Baixio e Jati, no Estado do Ceará, e Custódia, Salgueiro e Verdejante, em Pernambuco. Outros municípios listados em que também se tinha previsão de impactos, mas em menor medida, foram os municípios de Cabrobó e Sertânia, em Pernambuco, e Cajazeiras, Santa Helena, São José de Piranhas e Triunfo, na Paraíba (Consórcio Ecology Brasil et al., 2004), todos estes presentes na AID.

Além disso, o EIA-RIMA reconhece que os referidos municípios, que potencialmente seriam impactados, já vêm enfrentando limitações orçamentárias, as quais imporiam maiores dificuldades no atendimento das necessidades de expansão da infraestrutura das suas cidades, as quais podem ser agravadas pelo rápido processo de urbanização em curso (Consórcio Ecology Brasil et al., 2004). Assim, as configurações socioespaciais que emergem desse processo requerem formas de planejamento que venham a suprir as demandas sociais básicas nas municipalidades beneficiadas pelo Projeto. É preciso reconhecer, claro, que parte das migrações pode ter sido motivada por outras questões que não as do Projeto.

Embora algumas preocupações demográficas sejam explicitadas pelo EIA-RIMA do Projeto, este não realiza as análises das consequências da mobilidade populacional sobre a qualidade de vida dos recém-chegados e dos que já residiam na AID do Projeto de Transposição. Nesse contexto, para verificar possíveis impactos da mobilidade populacional sobre a vulnerabilidade sociodemográfica, adotou-se a proposta dos cenários de vulnerabilidade expostos na metodologia. O entendimento dos cenários pode aprimorar a criação de estratégias que respondam da melhor maneira às questões vindas do processo de urbanização que, nos últimos anos na região Nordeste, se intensificou não só nos polos regionais, mas também nos pequenos municípios (Ojima, 2013).

Os mapas dos índices e seus respectivos cenários estão listados na seguinte ordem: IVSD CF, IVSD CH, IVSD CS e o IVSD Geral. Assim, caso haja melhoras no IVSD dos municípios de um cenário para o outro, é possível supor que a população migrante contribuiu para maior carência de ativos, como redes de apoio, educação e/ou moradia, isto é, de capital social, humano e físico, o que compromete a composição sociodemográfica das áreas urbanas. Esse resultado implica menor capacidade de resposta e de adaptação pela população migrante aos riscos sociodemográficos existentes na AID. Caso contrário, mostra-se que a população migrante pos- 
sui um melhor conjunto de ativos e oportunidades e, consequentemente, melhores condições de resposta e adaptação, contribuindo em contrapartida para o bem-estar na AID do Projeto de Transposição.

Disto isto, a Figura 3 refere-se à dimensão Capital Físico (CF). Essa dimensão foi contemplada por quatro fatores: i) condição da ocupação domiciliar; ii) deficiência na infraestrutura domiciliar; iii) condição socioeconômica da mobilidade diária; e iv) carência na infraestrutura hídrica. Esses fatores ajudam no entendimento do quadro de vulnerabilidade sociodemográfica que o espaço em apreço expõe. É válido ressaltar que os primeiros fatores apresentam maior percentual explicativo e, consequentemente, os maiores impactos.
Considerando o volume de municípios em cada cenário, segundo as classificações do IVSD da dimensão CF, observa-se que o número de municípios com baixa vulnerabilidade aumentou de 10 para 13; com média baixa de 35 para 37; com média alta reduziu de 26 para 20; e com alta aumentou de 15 para 16 municípios. De modo geral, esses resultados indicam que houve melhorias na AID quando desconsideramos a população migrante com menos de quatro anos de residência na comparação entre o cenário observado e o cenário contrafactual. Esse resultado, portanto, evidencia que a mobilidade populacional intensificou a vulnerabilidade sociodemográfica na AID do Projeto de Transposição.

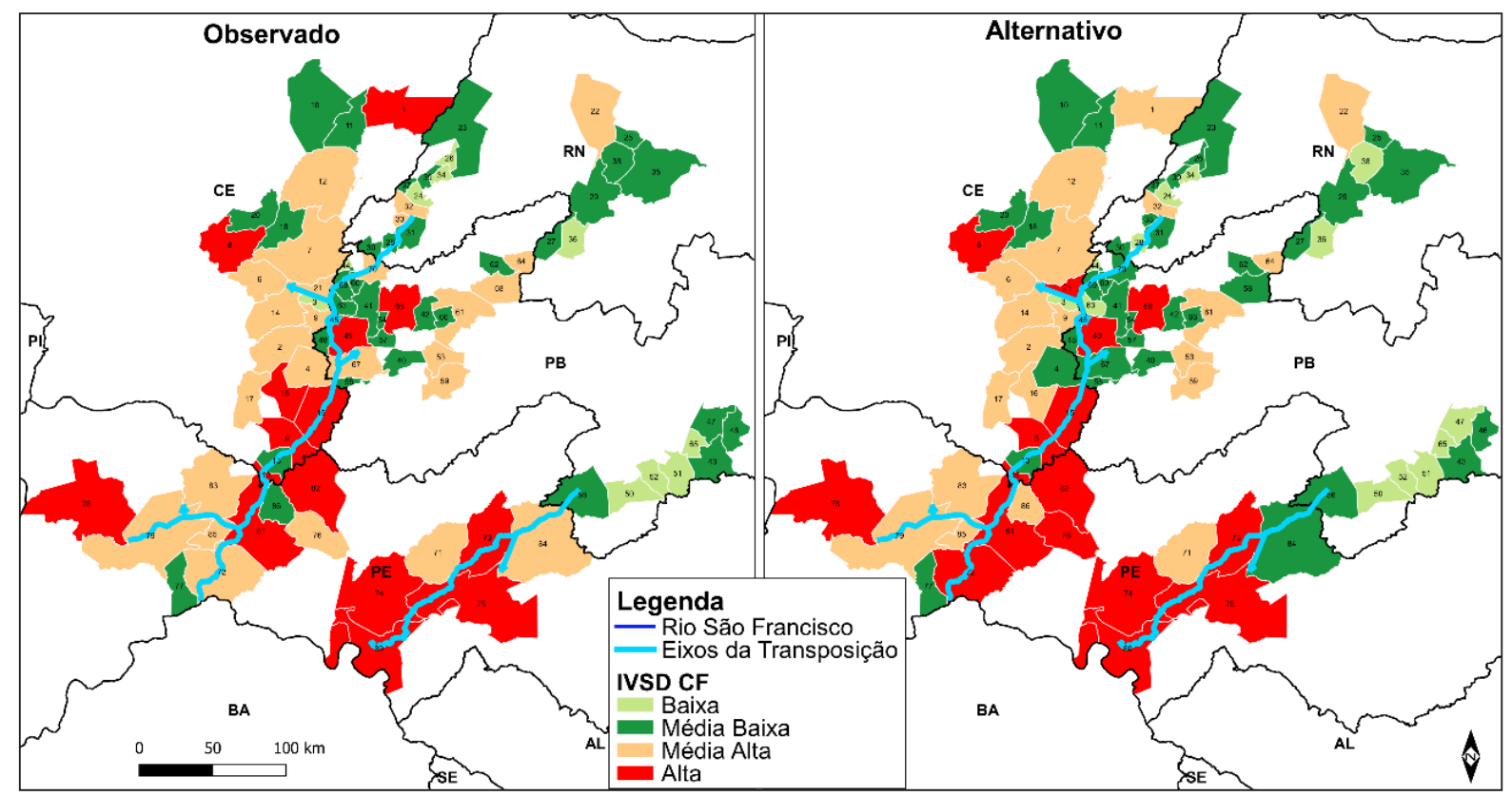

FIGURA 3 - Distribuição espacial da vulnerabilidade sociodemográfica, segundo os IVSD Observado (Cenário 1) e Alternativo (Cenário 2) da dimensão Capital Físico (CF) para a AID - 2010.

FONTE: IBGE, Censo Demográfico de 2010. 
Considerando o IVSD CF dos municípios elencados pela previsão de impacto pelo Projeto de Transposição (Consórcio Ecology Brasil et al., 2004), é possível estabelecer uma melhor conexão com os efeitos da mobilidade populacional provocados pelo referido empreendimento. Dessa maneira, o destaque fica com o município de Cabrobó, que registrou alta vulnerabilidade sociodemográfica quando excluída a população migrante. Isso mostra que os migrantes possuem papel importante para a melhoria do cenário da vulnerabilidade sociodemográfica deste município, tendo em vista a composição desta dimensão do IVSD. Ou seja, os migrantes têm melhores condições de moradia, de consumo, assim como melhores condições de deslocamento.

$\mathrm{O}$ acesso à habitação, condição básica de sobrevivência, permite ao indivíduo acessar outras oportunidades que não eram possíveis sem este ativo. Segundo Kaztman (1999), este ativo é fundamental para a vida familiar, em especial nos espaços urbanos, pois seu uso permite melhores condições de vida de caráter intergeracional, além de servir como ponto de apoio para outros membros da família para lograrem êxito em um espaço com maior leque de oportunidades. Isso demonstra que a população migrante com menos de quatro anos de residência em Cabrobó dispôs de ativos que a permitiram acessar a estrutura de oportunidades ali presente e, por conseguinte, garantiram também melhores condições de resposta e adaptação aos riscos sociais.

Contudo, a maior parte dos municípios registra situação inversa, ou seja, redução do grau de vulnerabilidade após a exclusão da população migrante. $\mathrm{O}$ que significa que os migrantes com menos de quatro anos de residência na AID do Projeto de Transposição têm baixa dotação dos ativos da dimensão capital físico. Em outras palavras, ao considerar os fatores que compõem essa dimensão, é possível afirmar que há um número significativo de pessoas residindo em domicílios com poucos dormitórios. Além disso, é possível colocar que possuem dificuldades na locomoção diária de casa para o trabalho, que por sinal é significativamente distante por levar mais de uma hora, bem como dificuldade de acesso à rede geral de água. Os principais casos referem-se aos municípios de Milagres (16) e Alto Santo (1), no Estado do Ceará, que saíram de uma situação de alta vulnerabilidade (cenário 1) para média alta (cenário 2). Além desses, há aqueles que passaram de média baixa para baixa vulnerabilidade de um cenário para o outro, como São Rafael (38) e José da Penha (28), no Rio Grande do Norte, e Santa Helena (63) e Cabeceiras (47), na Paraíba.

Portanto, a melhora do IVSD da dimensão CF para estes municípios indica que as condições habitacionais, de deslocamento e de acesso aos serviços públicos básicos são mais precárias para a população migrante com menos de quatro anos de residência na AID. Esse resultado vai ao encontro com o colocado por Hogan (2005), ao mencionar que os migrantes mais recentes encontrariam maiores dificuldades de adaptação no local de destino.

No que se refere ao IVSD da dimensão $\mathrm{Ca}$ pital Humano ( $\mathrm{CH}$ ) (Figura 4), este foi composto por quatro fatores: i) carência de capital humano; ii) condição de saúde crítica; iii) capital humano feminino precário; e iv) capital humano ocioso. Ao verificar o volume de municípios em cada classificação do IVSD desta dimensão, observa-se que de um cenário para o outro o número de municípios com baixo IVSD passa de 10 para 13; com médio baixo de 29 para 33; com médio alto de 40 para 33; e com alto IVSD o número de municípios nesta 


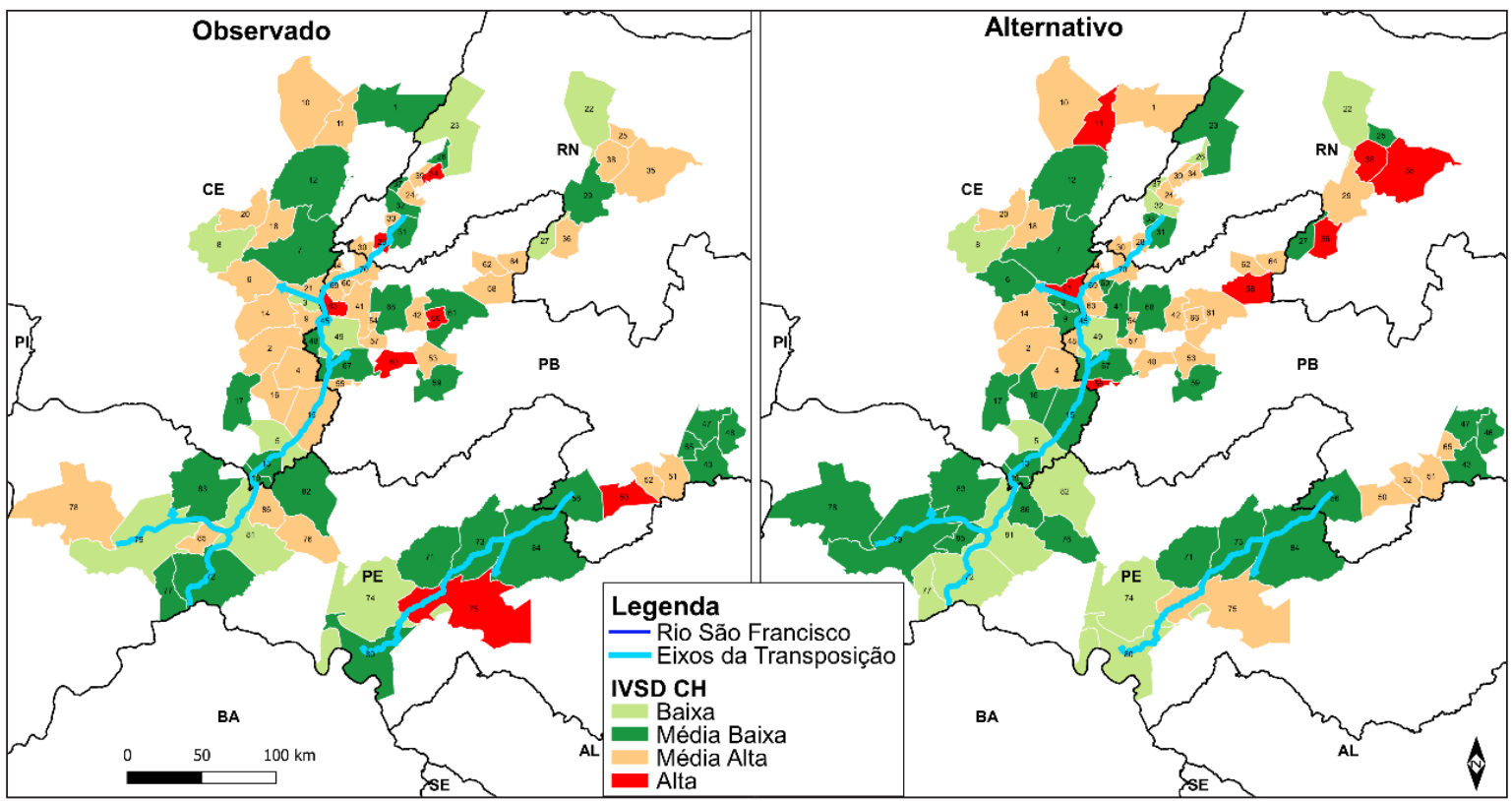

FIGURA 4 - Distribuição espacial da vulnerabilidade sociodemográfica, segundo os IVSD Observado (Cenário 1) e Alternativo (Cenário 2) da dimensão Capital Humano (CH) para a AID - 2010. FONTE: IBGE, Censo Demográfico de 2010.

condição permanece em sete nos dois cenários. De modo geral, esses resultados também apontam para uma menor vulnerabilidade quando se é retirada a mobilidade populacional, o que significa que esta mobilidade também traz maiores desafios à AID em termos de Capital Humano.

A melhora do IVSD da dimensão $\mathrm{CH}$, ao retirar a população migrante, é verificada especialmente na parte inicial dos eixos da transposição, isto é, nos municípios mais próximos ao Rio São Francisco, como em Salgueiro e Verdejante, em Pernambuco - espaços onde foram previstos os impactos mais significativos em termos de mobilização de mão de obra pelo EIA-RIMA. Portanto, onde se verificou a melhoria do IVSD é possível afirmar que a mobilidade populacional corresponde a um grupo de população com carência de capital humano e saúde, bem como em situação precária ou ociosa. Em outras palavras, a população migrante acima referida possui baixa escolaridade e significativa participação de jovens que não estudam e nem trabalham e são vulneráveis à pobreza. Além disso, nessa população há uma maior presença de pessoas mais velhas em relação às jovens, as quais apresentam alguma limitação física, seja de ouvir, ver, caminhar ou subir escadas. Isso mostra o quão crítico é o capital humano da população migrante, o que denota dificuldades de resposta e de adaptação ao local de destino, o que remete a maiores desvantagens sociais. Assim, é preciso um conjunto de estratégias que possam agir contra a reprodução da pobreza, visto que no cenário observado também 
se verifica certa ausência de ativos da dimensão capital humano, e a chegada dos migrantes nessas circunstâncias intensifica os desafios à mobilidade social dos indivíduos e das famílias sertanejas e, consequentemente, induz maior necessidade de investimentos em termos de saúde e educação pela gestão municipal.

Os indicadores de saúde e educação são indispensáveis para se ter noção do ingresso no mercado de trabalho e do exercício da vida como cidadão. Segundo Kaztman (1999), saúde e educação são dois ativos fundamentais que certamente podem ditar as perspectivas futuras dos indivíduos, sendo este último, por exemplo, um dos meios por excelência de mobilidade social ascendente.
Apenas os municípios de Umari (21), no Estado do Ceará, e Monte Horebe (55), na Paraíba, próximos aos eixos da transposição, registraram alto IVSD no segundo cenário. Isso mostra que os migrantes nessas localidades podem ser considerados subsídios fundamentais para lidar com a vulnerabilidade sociodemográfica local. Esse tipo de situação nos parece mais seleta, visto que prevalecem os casos em que a vulnerabilidade reduz com a saída da população migrante.

No que concerne ao IVSD da dimensão Capital Social (CS) (Figura 5), foram definidos pela análise fatorial três fatores que melhor explicam os dados originais. Os fatores foram: i) condição familiar precária; ii) condição assistencial; e iii) condição

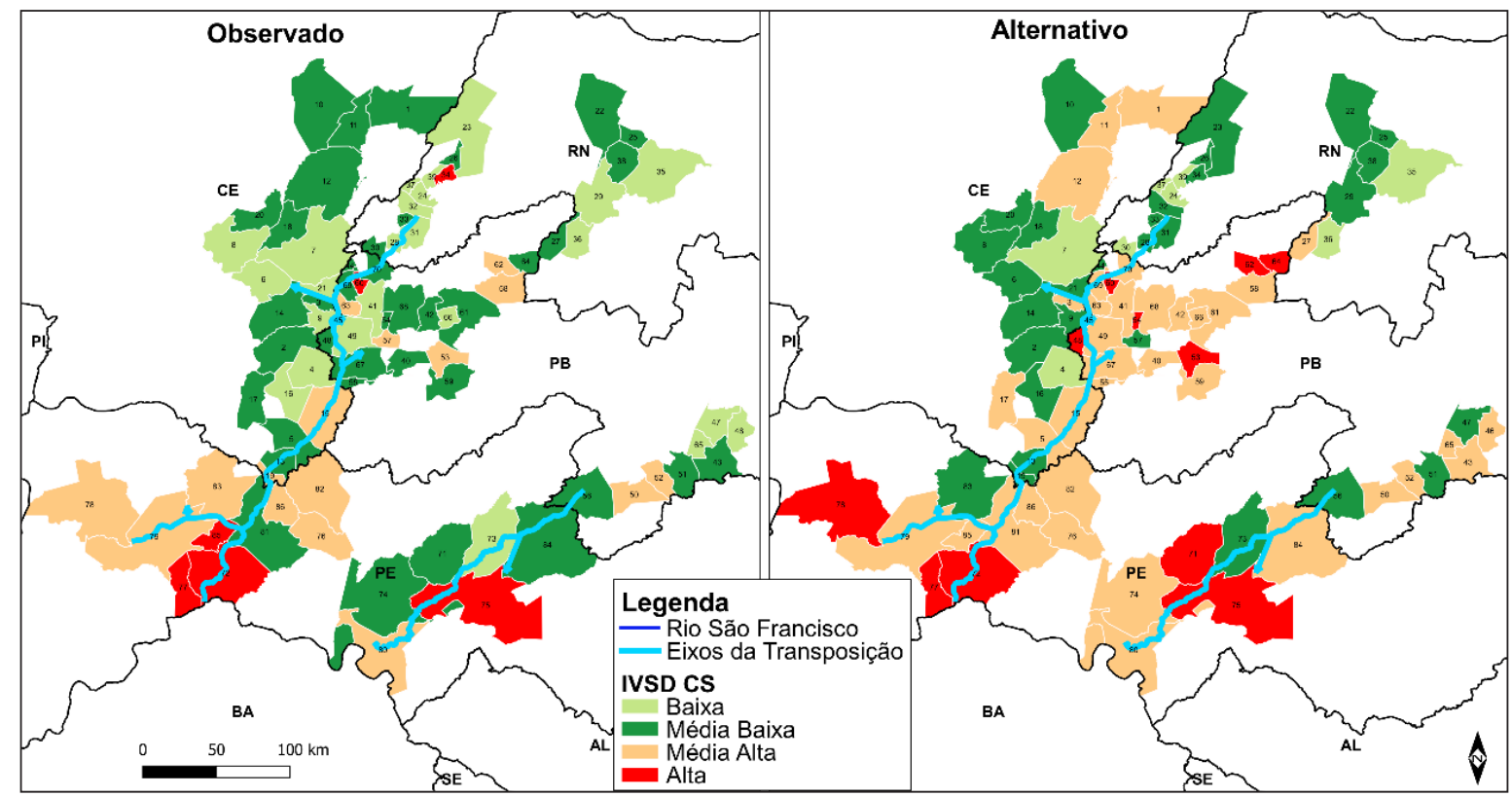

FIGURA 5 - Distribuição espacial da vulnerabilidade sociodemográfica, segundo os IVSD Observado (Cenário 1) e Alternativo (Cenário 2) da dimensão Capital Social (CS) para a AID - 2010.

FONTE: IBGE, Censo Demográfico de 2010. 
ocupacional precária. O número de municípios em cada classificação do IVSD da dimensão CS em cada cenário é apresentado a seguir: i) baixa vulnerabilidade passou de 24 para oito; média baixa vulnerabilidade passou de 40 para 30 ; média alta vulnerabilidade passou de 16 para 37; e alta vulnerabilidade passou de seis para 11 municípios.

No cenário factual (cenário 1), o número de municípios com média alta e alta vulnerabilidade são poucos, mas quando se verifica o segundo cenário, isto é, no contrafactual, é perceptível o crescimento do número de municípios nestas classificações, especialmente seguindo o curso da transposição, ou melhor, dos canais. A justificativa para esse mapa de vulnerabilidade pode ser a maior proteção social e assistencial da população migrante. Assim, os migrantes com menos de quatro anos de residência apresentam melhores condições de proteção social e assistencial, bem como melhores condições ocupacionais. Isso mostra o papel que os migrantes representam na AID em termos de Capital Social. Contudo, esses resultados mostram apenas que os migrantes com menos de quatro anos de residência são menos vulneráveis que o restante da população nos municípios destacados, mas esses migrantes ainda são vulneráveis por não terem acesso a todos os ativos necessários.

Em outras palavras, ainda é verificado nos grupos de migrantes um número significativo de famílias com rendimento inferior a $1 \frac{2}{2}$ salário mínimo e com crianças fora de escolas ou creches. É preciso salientar que uma parte substancial dessa população tem a possibilidade de sair ou lidar com a pobreza por terem acesso à proteção assistencial em programas como o PBF e o PETI.

Portanto, pelo fato de a população migrante ter uma vulnerabilidade sociodemográfica menor em termos de Capital Social, ameniza-se a problemática da reprodução da pobreza preexistente em alguns municípios da AID do Projeto de Transposição. Todavia, é necessária atenção a alguns municípios, como Cabrobró (72), Orocó (77), Terra Nova (85) e Ibimirim (75) no Estado de Pernambuco, Riacho da Cruz (34), no Rio Grande do Norte, e Poço de José de Moura (60), na Paraíba, que registraram alta vulnerabilidade sociodemográfica na dimensão Capital Social, segundo o cenário observado. Nessas localidades, portanto, há famílias com baixo rendimento per capita (menos de 1/2 salário mínimo), com boa parte ocupada em atividades agrícolas, tendo algumas apenas a proteção governamental (programas como o PBF e o PETI) como estratégia de adaptação às condições que são impostas cotidianamente.

Por fim, a Figura 6 apresenta a distribuição espacial do IVSD Geral dentro da AID, índice este resultante do agregado das dimensões anteriormente analisadas. Dito isso, é perceptível no primeiro cenário (observado) que poucos municípios da AID se encontram nos extremos do IVSD Geral. Nesse contexto, apenas três municípios apresentaram baixa vulnerabilidade - São Domingos do Cariri (65, em PB), Baixio (3, em CE) e Apodi (23, em RN) - e dois municípios alta vulnerabilidade - Mauriti (15, em CE) e Ibimirim (75, em PE). Já no cenário alternativo, apenas São Francisco do Oeste (37, em $\mathrm{RN})$ ficou com baixa vulnerabilidade e Ibimirim (75, em PE), que permaneceu com alta vulnerabilidade sociodemográfica.

Ao se desconsiderar a população migrante (cenário alternativo), verificou-se que a maioria dos municípios registrou piora no IVSD Geral. Isso significa que os migrantes com menos de quatro anos de residência possuem ativos que contribuem 


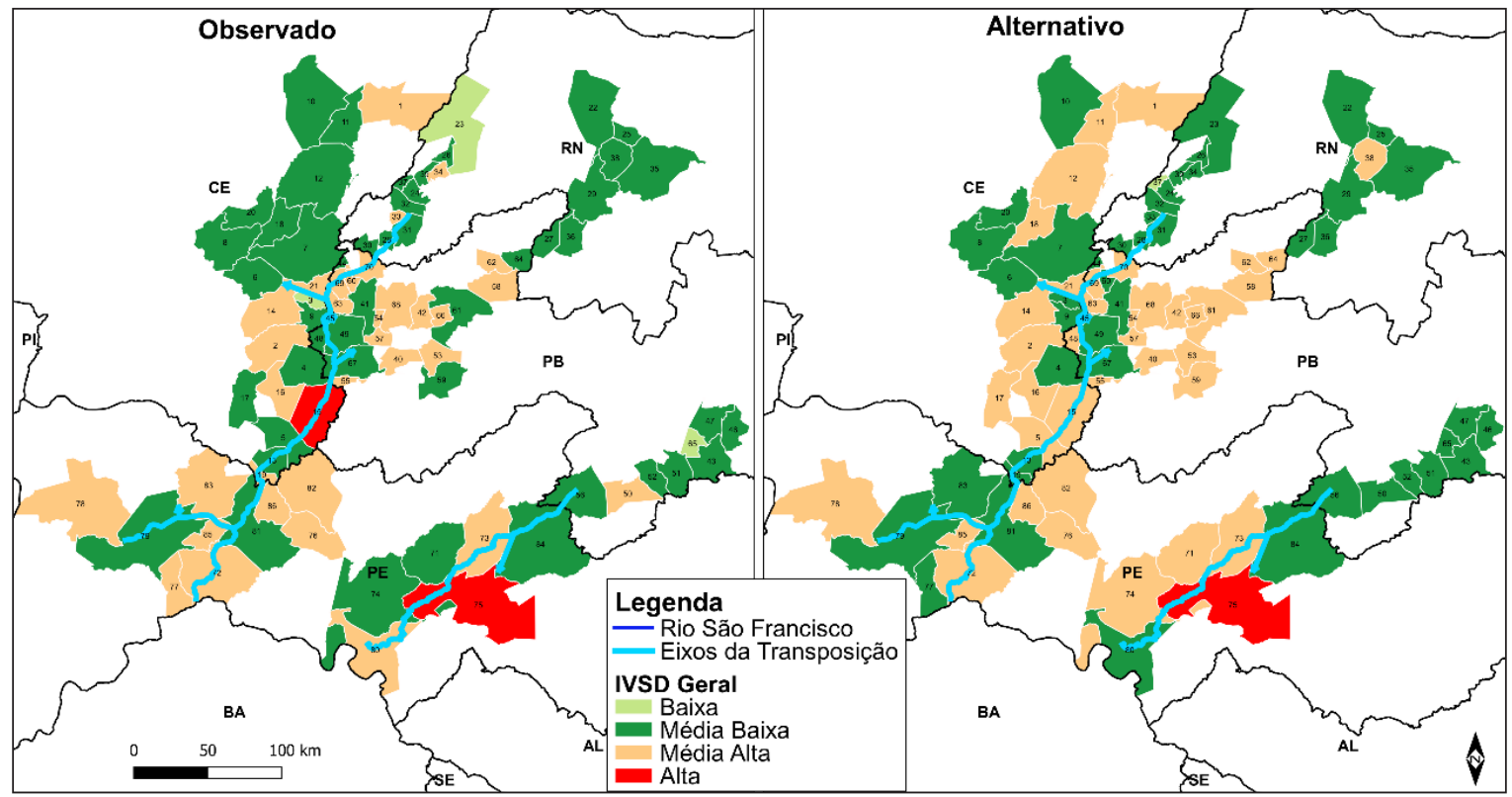

FIGURA 6 - Distribuição espacial da vulnerabilidade sociodemográfica, segundo os IVSD Geral Observado (Cenário 1) e Alternativo (Cenário 2) para a AID - 2010.

FONTE: IBGE, Censo Demográfico de 2010.

com a melhora do quadro de vulnerabilidade sociodemográfica da AID. Considerando as dimensões que compõem o referido índice, observou-se que a dimensão capital social foi a responsável pelo maior peso nos resultados registrados para a AID. Portanto, os migrantes recentes possuem maior dotação de capital social, ou seja, maior proteção social e assistencial, assim como melhores condições ocupacionais; características que colocam a população dos municípios em uma situação de vulnerabilidade menos preocupante. Contudo, as dificuldades de acesso a recursos da dimensão capital social (proteção assistencial, emprego formal e renda), assim como das dimensões capital humano (educação e serviços de saúde) e físico (moradia, bens duráveis como geladeira, e rede geral de água), que são mais críticos, colocam os migrantes na AID em condição desfavorável.

\section{Considerações finais}

Em síntese, considerando os índices de vulnerabilidade, é notável que a AID apresenta fragilidades estruturais ou deficiências, especialmente em termos de capital físico e humano, o que pode ser reflexo da incapacidade de lidar com as demandas de infraestrutura urbana (moradia, saneamento básico e escolas, por exemplo) que surgem em espaços que já apresentam limitações orçamentárias. A dificuldade de acesso a esses ativos, em especial pela população migrante residente nestas áreas, 
pode implicar maiores dificuldades de adaptação e maior exposição à pobreza e a tendência à mobilidade socioeconômica descendente. Somadas essas condições às já existentes, esses espaços são colocados em situação mais preocupante, o que leva à urgência de planejamento urbano mais eficiente para atender as demandas emergentes na AID do Projeto de Transposição. Portanto, isso mostra que a mobilidade populacional induzida pela Transposição do Rio São Francisco trouxe consigo maiores desafios ao bem-estar dos espaços urbanos, haja vista a composição populacional e sua distribuição socioespacial implicarem maior vulnerabilidade sociodemográfica.

Desta maneira, é preciso uma maior mobilização de recursos estratégicos para prevenir ou reverter o quadro de reprodução da pobreza, de modo que se melhore as condições de capital humano, físico e social da população sertaneja. Se as condições de acesso aos serviços básicos, como água e esgotamento sanitário, ainda são precárias na região, isso pode ser um dos entraves à fase de operação do Projeto de Transposição. Em outras palavras, terá água nos canais, mas haverá dificuldades para distribuição adequada e, assim, o acesso à água ainda persistirá como uma problemática ao bem-estar da população no sertão nordestino.

É possível lançar mão de algumas hipóteses futuras considerando os achados nesta pesquisa para a AID do Projeto de Transposição. Umas das principais hipóteses são: o aumento da mobilidade populacional, em especial dos deslocamentos pendulares em relação à migração, já que foram verificadas dificuldades de acesso aos recursos da dimensão capital físico, o que pode levar a população a morar em residências mais afastadas dos grandes centros urbanos; menor capacidade de resposta e adaptação dos imigrantes, devido à fragilidade estrutural que persiste na AID; maior dificuldade de atendimento às demandas de infraestrutura que emergem nos locais de destino mais próximos aos eixos da transposição; e, consequentemente, aumento da proporção de pessoas em risco sociodemográfico.

Enfim, a análise aqui desenvolvida deixa claro que a mobilidade populacional joga um papel importante no contexto de vulnerabilidade sociodemográfica da população, particularmente em relação aos municípios da AID do Projeto de Transposição. Assim, confirma-se a importância de avaliar a mobilidade populacional para além do seu mero impacto no volume da população. Desconstruir a ideia de que movimentos populacionais para as áreas urbanas sempre trazem efeitos negativos para a estrutura urbana e vice-versa. Conforme demonstramos, há contextos nos quais a vulnerabilidade aumenta com a presença dos migrantes e outros em que ela diminui, independentemente do impacto que possa haver sobre o crescimento ou não do volume populacional do município. Entretanto, em geral, a presença de migrantes tende a ser mais positiva do que negativa em termos das dimensões da vulnerabilidade social aqui analisadas.

\section{Agradecimentos}

Esta pesquisa conta com apoio financeiro da Coordenação de Aperfeiçoamento de Pessoal de Nível Superior - Brasil (CAPES) - Código de Financiamento 001. Também contou com o apoio do Conselho Nacional de Desenvolvimento Científico e Tecnológico (CNPq) - processo: 306302/2017-9 "Por uma demografia da seca: migração, políticas sociais e adaptação no semiárido setentrional". 


\section{Referências}

Busso, G. Vulnerabilidad sociodemográfica en Nicaragua: un desafio para el crecimiento económico y la reducción de la pobreza. Serie Población y Desarrollo, № 29. CELADE, Santiago de Chile, 2002. Disponível em: <repositorio.cepal. org/bitstream/handle/11362/7167/S028572_es.pdf?sequence $=1 \&$ isAllowed $=\mathrm{y}>$.

Busso, G. Pobreza, exclusión y vulnerabilidad social. Usos, limitaciones y potencialidades para el diseño de políticas de desarrollo y de población. In: VIII Jornadas Argentinas de Estudios de Población (AEPA), Tandil, Provincia de Buenos Aires, 2005. Publicado en CD. Disponível em: $<$ http:// www.redaepa.org.ar/jornadas/viii/AEPA/B10/Busso, $\% 20$ Gustavo.pdf>.

Cepal - Comisión Económica para América Latina y el Caribe. Sociodemographic vulnerability: old and new risks for communities, households and individuals. Summary and conclusions. Brasília: UNA, 2002. Disponível em: $<$ https://repositorio.cepal.org/bitstream/handle/11362/13023/ S023170_en.pdf?sequence $=1>$.

Consórcio Ecology Brasil et al. Projeto de Integração do Rio São Francisco com Bacias Hidrográficas do Nordeste Setentrional: consolidação dos estudos ambientais. [s. 1.: s.n.], 2004. Disponível em: <http://licenciamento.ibama. gov.br/Recursos\%20Hidri cos/Integracao $\% 20$ Sao $\% 20$ Francisco/EIA/Textos/EIA\%20Consolidado\%20Item\%20 $11 \% 20 \mathrm{An} \%$ E1lise $\% 20 \mathrm{de} \% 20$ Impactos.pdf $>$.

Costa, P. V. M. Mobilidade populacional e vulnerabilidade sociodemográfica no contexto da transposição do Rio São Francisco. Natal, Dissertação (Mestrado em Demografia) - PPGDEM/UFRN, 2020.

Cunha, J. M. P.; Hogan, D. J.; Jakob, A. A. E.; Carmo, R. L. A vulnerabilidade sociodemográfica no contexto metropolitano: o caso de Campinas. In: Cunha, J. M. P. (Org.). Novas metrópoles paulistas: população, vulnerabilidade e segregação. Campinas: NEPO/UNICAMP, 2006. p. 143-168. Disponível em: https://www.nepo.unicamp.br/ publicacoes/livros/vulnerabilidade/index.htm

Fávero, L. P.; Belfiore, P.; Silva, F. L.; Chan, B. L. Análise de dados: modelagem multivariada para tomada de deci- sões. Rio de Janeiro: Elsevier-Campus, 2009. Disponível em: https://edisciplinas.usp.br/pluginfile.php/4069032/ mod_resource/content/1/Favero_07_AnaliseFatorial.pdf

Gonzáles, M. L. M. Vulnerabilidad socio-demográfica en el Gran Córdoba: Diagnóstico y perspectivas en el período 2001-16. In: IX Jornadas Argentinas de Estudios de Población, 2007. Disponível em: http://www.redaepa.org.ar/ jornadas/ixjornadas/resumenes/Se27--Prospectiva_Arriaga/ GonzalezVulnerabilidad2001_16.pdf

Hogan, D. J. Mobilidade populacional, sustentabilidade ambiental e vulnerabilidade social. Revista Brasileira de Estudos da População, São Paulo, 22(2), 323-338, 2005. Disponível em: http://www.scielo.br/pdf/rbepop/v22n2/ v22n2a08

Kaztman, R. (Coord.). Activos y estructuras de oportunidades. Estudios sobre las raíces de la vulnerabilidad social en el Uruguay (LC/MVD/R.180). Montevideo, ECLAC office in Montevideo, 1999. Disponível em: <https://repositorio.cepal.org/bitstream/handle/11362/28651/LCmvdR180_es.pdf? sequence $=1$ \&isAllowed $=\mathrm{y}>$. Acesso em: $30 \mathrm{de}$ abr. 2019 .

Macedo, C. E. G.; Bassani, V. D. S. Vulnerabilidade socioeconômica em Porto Alegre: uma abordagem com análise multivariada. In: Anais do XVII Encontro Nacional de Estudos Populacionais, ABEP. Caxambu-MG, 2010. Disponível em: $<$ http://www.abep.org.br/publicacoes/index. php/anais/article/view/2308>.

Melo, H. P. Gênero e pobreza no Brasil. Relatório final do Projeto Governabilidad Democratica de Género en America Latina y el Caribe. Comissão Econômica para América Latina e Caribe - CEPAL. Secretaria Especial de Políticas para as Mulheres - SPM. Brasília, 2005. Disponível em: http:// www.observatoriodegenero.gov.br/menu/publicacoes/ outros-artigos-e-publicacoes/genero-e-pobreza-no-brasil/ view? searchterm $=\mathrm{g} \% \mathrm{C} 3 \%$ AAnero $\% 20 \mathrm{e} \% 20$ pobreza

Ojima, R. Urbanização, dinâmica migratória e sustentabilidade no Semiárido Nordestino: o papel das cidades no processo de adaptação ambiental. Cadernos Metrópole (PUCSP), 15, 35-54, 2013. Disponível em: https://revistas. pucsp.br/index.php/metropole/article/view/15815 
Ojima, R.; Marandola Jr., E. Mobilidade populacional e um novo significado para as cidades: dispersão urbana e reflexiva na dinâmica regional não metropolitana. Revista Brasileira de Estudos Urbanos e Regionais (ANPUR), 14, 103-116, 2012.

Prieto, L. M. B. Vulnerabilidad sociodemográfica en el aglomerado urbano de Bahía Blanca - Argentina. In: Anais do XVI Encontro Nacional de Estudos Populacionais. Caxambu-MG - Brasil, 29 de setembro a 03 de outubro de 2008. Disponível em: https://www.abep.org.br/publicacoes/ index.php/anais/article/view/1817

Queiroz, S. N. Migrações, retorno e seletividade no mercado de trabalho cearense. Campinas, Tese (Doutorado em Demografia) - UNICAMP/IFHC, 2013.

Rigotti, J. I. R. Técnicas de mensuração das migrações, a partir de dados censitários: aplicação aos casos de Minas Gerais e São Paulo. Belo Horizonte, Tese (Doutorado em Demografia) - CEDEPLAR/UFMG, 1999.

Rodríguez, J. Vulnerabilidad demográfica: una faceta de las desventajas sociales. Santiago de Chile: Comissão Econômica para América Latina e Caribe - CEPAL, 2000.
79 p. Disponível em: https://repositorio.cepal.org/bitstream/ handle/11362/7185/S2000937.pdf?sequence=1

Rodríguez, J. Vulnerabilidad y grupos vulnerables: un marco de referencia conceptual mirando a los jóvenes. Serie: Población y Desarrollo. Santiago de Chile: Comissão Econômica para América Latina e Caribe - CEPAL, agosto de 2001. Disponível em: https://repositorio.cepal.org/bitstream/handle/11362/7150/S018659_es.pdf

Rodríguez, J. Vulnerabilidade sociodemográfica: antigos e novos riscos para a América Latina e o Caribe. In: Cunha, J. M. P. da (Org.). Novas metrópoles paulistas: população, vulnerabilidade e segregação. Campinas: NEPO/Unicamp, 2006. p. 95-142. Disponível em: https://www.nepo.unicamp. br/publicacoes/livros/vulnerabilidade/index.htm

Viana, J. P. Ações do governo federal na área de influência do Projeto de Integração do Rio São Francisco com bacias hidrográficas do Nordeste Setentrional: uma avaliação dos investimentos nos municípios do Plano de Ação. Texto para Discussão (IPEA), v. 1965, 2014. Disponível em: http://www.ipea.gov.br/portal/images/stories/PDFs/TDs/ td_1965.pdf 